\title{
AGE ESTIMATION BY EVALUATING PELVIC BONE TRABECULATION USING CT-SCAN OF AN EGYPTIAN SAMPLE
}

\author{
Riham F. Hussein*, Dina A. Shokry*, Manal M. Ismail*, Manar H. Abd-Elsatar** and \\ Samah F. Ibrahim* \\ Forensic Medicine \&Clinical Toxicology Department*, Radiology Department**, faculty of \\ medicine- Cairo University
}

\begin{abstract}
:
Forensic anthropology has been one of the fastest growing medico-legal disciplines both in its contribution to the practical needs of the legal system and research accomplishments. Pubic, sacral body and sacral ala trabeculations were studied in 200 abdomino-pelvic CT from Kasr al Aini Radiology department period from 10/2014 till 10/2015. The examined group aged from 20- 60 years, they were classified into four age groups considering 10 years' interval. There was a significant difference between the 4 age groups regarding these trabeculations. Moreover, significant correlations between age and trabeculations phases were found in all age groups.
\end{abstract}

Key words: CT- trabeculations - pelvic bones

\section{INTRODUCTION}

Human identification depending on radiological image technique analysis is a proper and practical method in forensic science field. Skeletal identification has a long tradition in both physical and forensic anthropology. The process begins with formulation of a biological profile (osteobiography); specifically estimate sex, age, ethnicity and stature. (Franklin, 2010).

Estimation of age is one of the important factors that help in human identification. Moreover, it is needed in many civil and criminal situations (Shetty, 2009). Age estimation using different bones has been conducted to assess their accuracy and reliability (Bokariya et al.; 2011).

Trabecular bone, fills the medullary cavity of long bones and also makes up the majority of vertebral bodies, is more affected by metabolic processes and other conditions predisposing to bone loss. With aging, the balance of remodeling favors bone resorption over formation leading to a net thinning of trabecular bone over time (Dempster, 2006). CT scans allow researchers to investigate subsurface features of the trabecular bone, decreasing the bone density, the trabecular interconnection until they disappear, and increasing the medullar space (Villa et al.; 2013).

\section{AIM OF THE STUDY}

This research was aiming at focusing on the value of CT in age determination using trabeculations degree of pelvic bone in addition to Construction of Egyptian regression equations to estimate the age.

\section{METHODOLOGY}

A sample of 200 randomly selected high resolution multi-slice abdominopelvic CT scans were reviewed in the 
radiology department at Kasr Al-Aini hospital during the period from $10 / 2014$ to $10 / 2015$ using Siemens somatom emotion 16 slice. The research protocol was approved by ethical committee of the forensic medicine department Cairo University (15/7/2014). Patients with history of trauma, surgery, pathological lesions or poor image quality in the studied region were excluded from the study. We studied ages less than 60 years to avoid the osteoporotic changes. Pubic bone, sacral ala and sacral body trabeculations were reported in all samples. Bone trabeculations were detected by a trained radiologist Fig $\mathbf{1}$ and divided into 4 phases according to villa et al. (2013)

- Phase 1: the trabecular bone is very dense and homogenous; the interior of the bone seems homogenously filled with trabecular bone. There is one dominant shade of gray, lighter than the surrounding soft tissues.

- Phase 2: the trabecular bone is still predominantly dense and homogenous, but there are some areas (less than 20\%) showing a less dense structure. There are two shades of gray, but the lighter one is dominant.

- Phase 3: the trabecular bone further decreases in density; the trabecular bone is less dense than phase 2; furthermore, there are some areas with very large trabecular structure or areas where the trabecular bone is completely disappeared. Those areas cover less than $50 \%$ of the surface. There is no single dominant shade of gray.

- Phase 4: the impression is that the majority (more than $>50 \%$ ) of the area is "empty". There are only few areas with remains of trabecular bone. The dominant shade is dark.

No suitable standard reference point for trabeculations could be identified for all subjects in one slice, so 10 to 20 slices have been evaluated to detect the most frequent phase to be the assigned on 


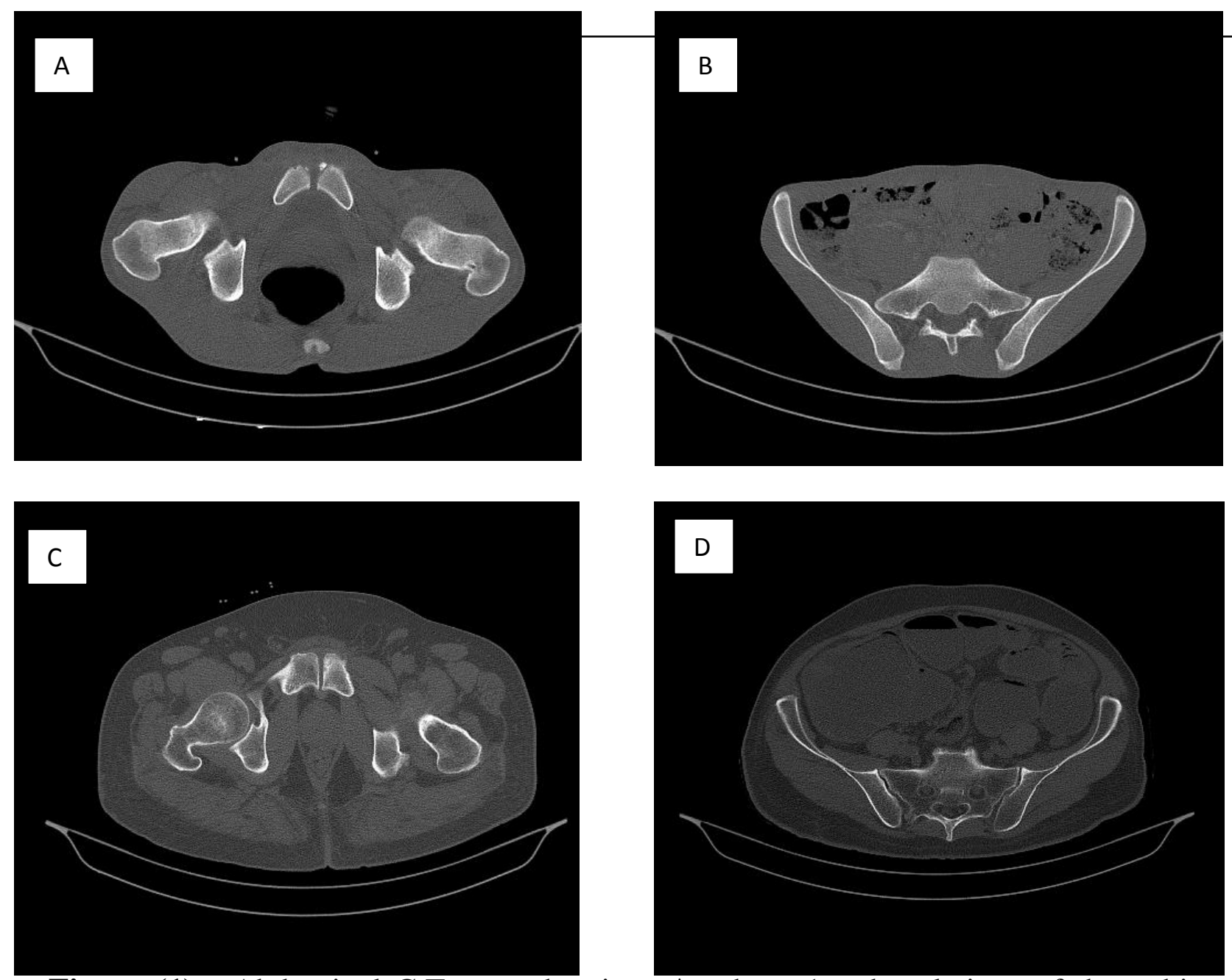

Figure (1): Abdominal C.T scan showing: A: phase 1 trabeculations of the pubic bone. B: phase 2 trabeculations of the sacral ala. C: phase 3 trabeculations of pubic bone. $\mathrm{D}$ : phase 4 trabeculations in pubic and sacral ala

\section{Data analysis:}

The data was coded and entered using the statistical package SPSS version 15 . The data was summarized using descriptive statistics: mean, standard deviation, minimal and maximum values for quantitative variables and number and percentage for qualitative values. Statistical differences between groups were tested using Chi Square test for qualitative variables, independent sample t test for quantitative normally distributed variables. p-values less than or equal to 0.05 were considered statistically significant.

\section{RESULTS:}

\section{CT scans sample:}

The studied sample included 200 subjects (100 males, 100 females) whose ages ranged between 20 and 60 years, with mean age of $(44.7 \pm 12.02$ years). They were classified into four groups, as follows: group (1) 21-30 years, their mean age was 26.18 \pm 3.38 years, group (2) 31-40 years; their mean age was $36.62 \pm 2.83$ years, group (3) 41-50 years, their mean age was $45.94 \pm 2.73$ years and group (4) 51-60 years, their mean age was 56.84 \pm 2.97 years 


\section{Description of pubic bone trabeculations:}

This study declared that phase (3), and phase (4) trabeculations were the most frequent stages in the studied sample as they were found in 66 cases (33\%) and 68 cases $(34 \%)$ respectively. Phase (1) pubic bone trabeculations was detected more in age group (1) 28 cases $(71.8 \%)$ while phase 2 was detected more in age group (2) 17 cases $(50 \%)$ followed by age group (1) and
(3) 10 cases each. Phase (3) was detected more in age group (3), 34 cases $(68 \%)$ while phase (4) was detected more in age group (4), 62 cases (80.5\%) (Table1). Moreover, a statistical significant positive correlation was detected between the age of the studied groups and the trabeculations of the pubic bone $(\mathrm{R}=$ 0.875, p<0.001**) (Fig. 2).

Table (1): Pubic trabeculations scores in different age groups and their significance in the studied subjects (Chi-square test)

\begin{tabular}{|c|c|c|c|c|c|c|c|c|}
\hline Age groups & Group (1) & Group (2) & Group(3) & Group(4) & Total $(\%)$ & \multicolumn{3}{|c|}{ Chi- Square test } \\
\hline \begin{tabular}{|c|}
$\begin{array}{l}\text { Pubic } \\
\text { trabeculations } \\
\text { phase }\end{array}$ \\
\end{tabular} & & & & & & Value & df & p-value \\
\hline 1 & $28(71.8 \%)$ & $1(2.9 \%)$ & $0(0 \%)$ & $0(0 \%)$ & $29(14.5 \%)$ & \multirow[t]{5}{*}{260.2} & \multirow[t]{5}{*}{9} & \multirow{5}{*}{$<0.001 * *$} \\
\hline 2 & $10(25.6 \%)$ & $17(50 \%)$ & $10(20 \%)$ & $0(0 \%)$ & $37(18.5 \%)$ & & & \\
\hline 3 & $1(2.6 \%)$ & $16(47.1 \%)$ & $34(68 \%)$ & $15(19.5 \%)$ & $66(33 \%)$ & & & \\
\hline 4 & $0(0 \%)$ & $0(0 \%)$ & $6(12 \%)$ & $62(80.5 \%)$ & $68(34 \%)$ & & & \\
\hline Total & $39(100 \%)$ & $34(100 \%)$ & $50(100 \%)$ & $77(100 \%)$ & $200(100 \%)$ & & & \\
\hline
\end{tabular}

**Significance was set at $\mathbf{p} \leq \mathbf{0 . 0 1}$

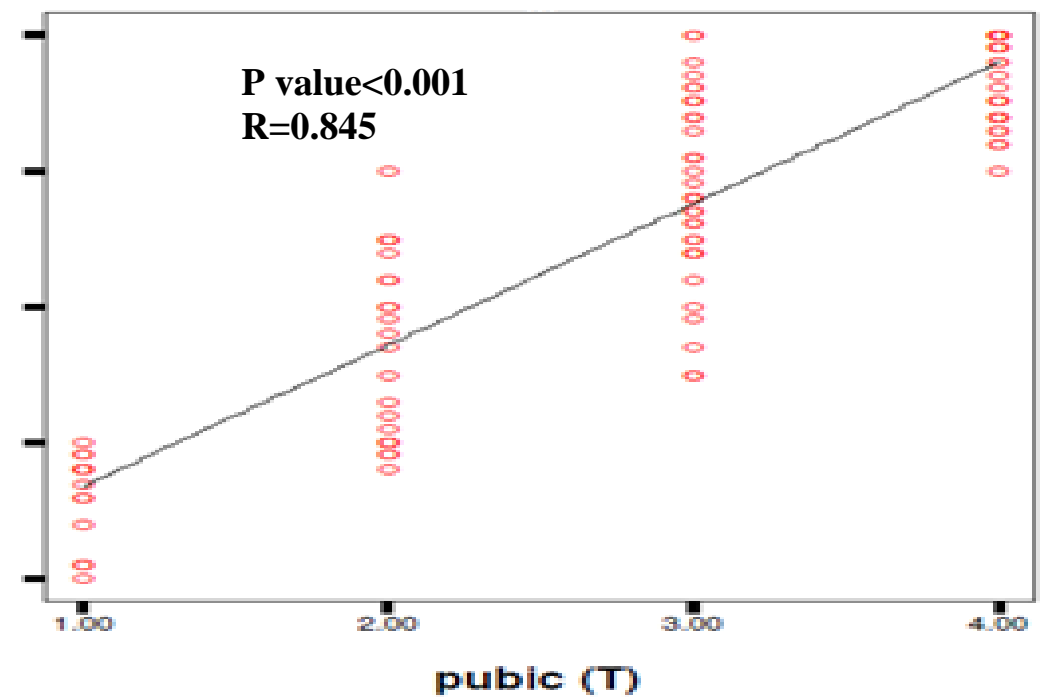

Figure (2): Scatter plot showing the correlation between known age and pubic bone trabeculation phases.

Description of Sacral ala trabeculations
This study declared that phase (3), and phase (4) trabeculations were the 
most frequent stages in the studied sample as they were found in 57 cases $(29 \%)$ and 90 cases $(45 \%)$ respectively. Phase (1) pubic bone trabeculations was detected more in age group (1) 17 cases $(44 \%)$ while phase 2 was detected more in age group (1) 21 cases (54\%). Phase (3) was detected more in age group (3), 29 cases (58\%) while

Table (2): Sacral ala trabeculations phases in different age groups and their significance among the studied subjects (Chi-Square test)

\begin{tabular}{|c|c|c|c|c|c|c|c|c|}
\hline Age & Group (1) & Group (2) & Group (3) & Group (4) & Total (\%) & \multicolumn{3}{|c|}{ Chi-square test } \\
\hline $\begin{array}{l}\text { Sacral ala } \\
\text { phase }\end{array}$ & & & & & & & & \\
\hline 1 & $17(43.6 \%)$ & $0(0 \%)$ & $0(0 \%)$ & $0(0 \%)$ & $17(8.5 \%)$ & value & df & p value \\
\hline 2 & $21(53.8 \%)$ & $12(35.3 \%)$ & $3(6 \%)$ & $0(0 \%)$ & $36(18 \%)$ & \multirow[t]{4}{*}{213.6} & \multirow[t]{4}{*}{9} & \multirow[t]{4}{*}{$<0.001 * *$} \\
\hline 3 & $1(2.6 \%)$ & $17(50 \%)$ & $29(58 \%)$ & $10(13 \%)$ & $57(28.5 \%)$ & & & \\
\hline 4 & $0(0 \%)$ & $5(14.7 \%)$ & $18(36 \%)$ & $67(87 \%)$ & $90(45 \%)$ & & & \\
\hline Total & $39(100 \%)$ & $34(100 \%)$ & $50(100 \%)$ & $77(100 \%)$ & $200(100 \%)$ & & & \\
\hline
\end{tabular}

** Significance was set at $\mathrm{p} \leq 0.01$

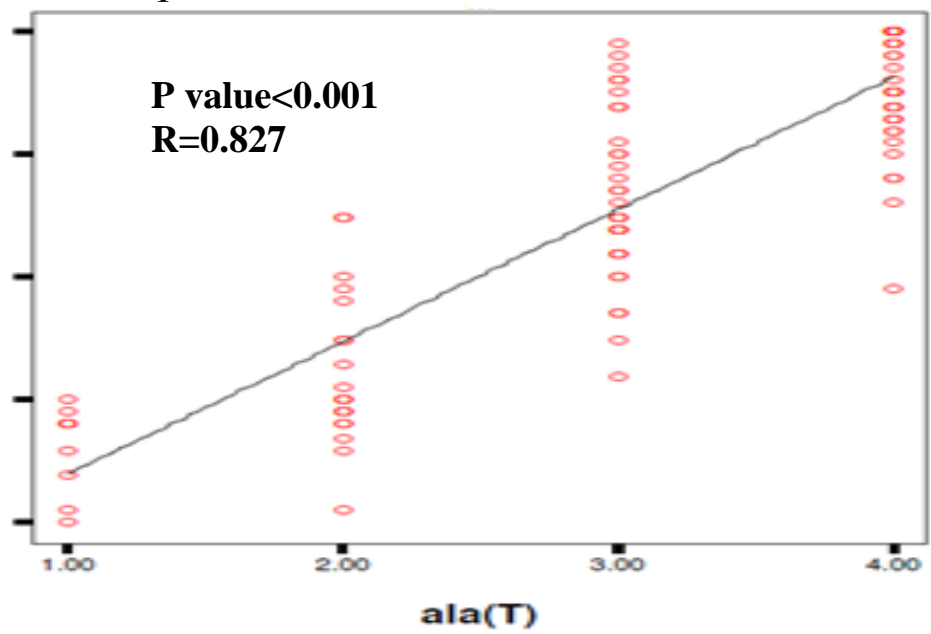

Figure (3) Scatter plot showing the correlation between known age and sacral ala trabeculations phases.

\section{Description of Sacral body} trabeculations phases:

This study declared that phase (2), and phase (3) trabeculations were the most frequent stages in the studied sample as they were found in 59 cases $(30 \%)$ and 68 cases $(34 \%)$ respectively. Phase (1) pubic bone trabeculations was detected more in age group (1) 36 cases $(92 \%)$ while phase 2 was detected more in age group (3) 29 cases phase (4) was detected more in age group (4), 67 cases (87\%) (Table 2). Moreover, a statistical significant positive correlation were detected between the age of the studied groups and the trabeculations of the pubic bone $(\mathrm{R}=0.827, \mathrm{p}<0.001 * *$ for both) (Fig. 3). 
Table (3): Sacral body CT trabeculations phases in different age groups and their significance among the studied group (Chi-square test)

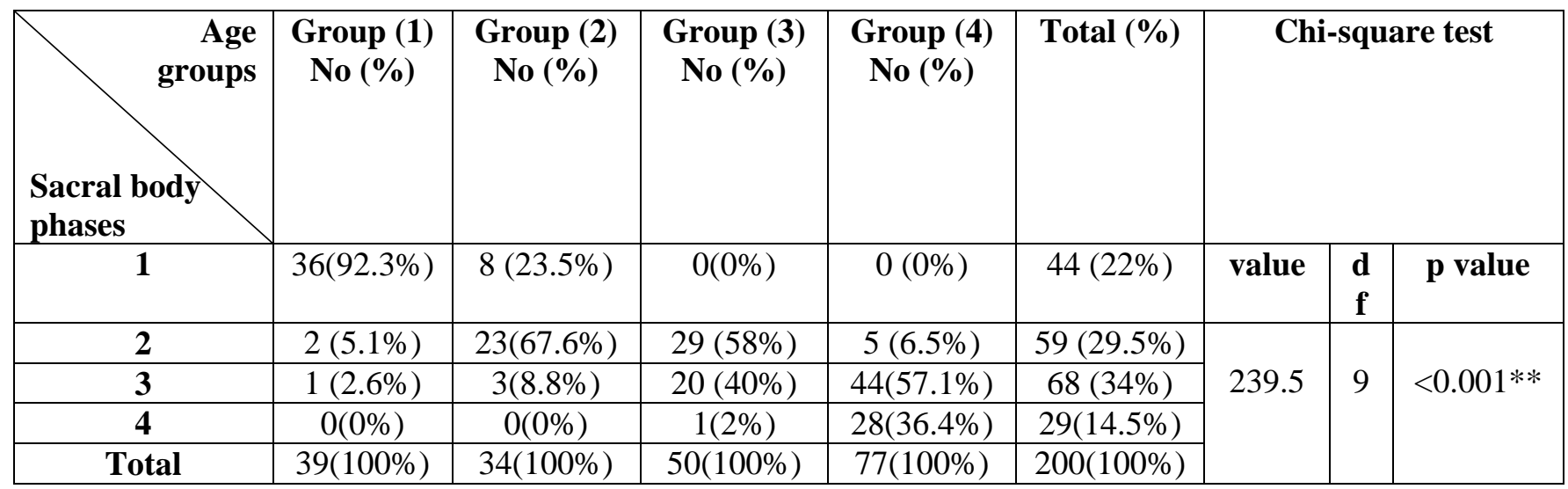

**Significance was set at $\mathrm{p} \leq 0.01$ level

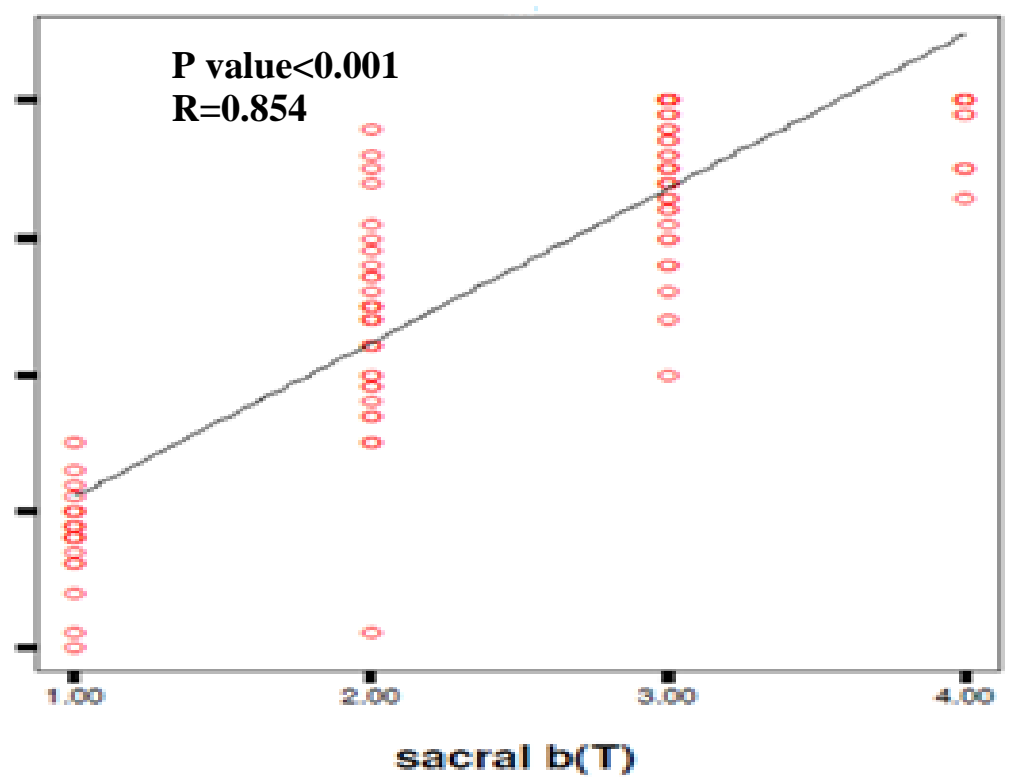

Figure (4): Scatter plot showing the correlation between known age and sacral body trabeculations phases.

\section{Composite score:}

It is the statistical summation of the trabeculations phases of the pubic bone, sacral body and sacral ala for the same person with 3 as minimum, 12 as a maximum value. Its mean value was
$8.38 \pm 2.88$. A highly significant positive correlation was found between the age and the composite score in the studied group with $\mathrm{R}$ value 0.908 ( $<<0.000 * *)$

(Table 4).

Table (4): Mean values and Spearman's correlation between age and composite trabeculations score among studied subjects

\begin{tabular}{|c|c|c|c|c|}
\hline Composite score & Number & Mean \pm SD & R value & p value \\
\hline Studied group & 200 & $8.38 \pm 2.88$ & 0.908 & $<0.001^{* *}$ \\
\hline
\end{tabular}

**Significance was set at $\mathrm{p} \leq 0.05$ 


\section{Regression equation:}

Considering the known individual age as the dependent variable and the composite score as predictor, a linear regression correlation between known individual age and composite score was found; its accuracy was evaluated using
$\mathrm{R}^{2}$ and confident interval (95\%) as shown in (Table 5 and Fig. 5). Furthermore, a linear regression equation was constructed for age estimation as follow:

$$
\text { Age }=6.696+3.796 \times \text { composite }
$$
score

Table (5): Correlation between composite score and the studied group (one-way ANOVA)

\begin{tabular}{|c|c|c|c|c|c|}
\hline \multirow{2}{*}{ Sig. } & \multirow{2}{*}{ B value } & \multicolumn{3}{|c|}{ O5\% confidence interval } & \multirow{2}{*}{$\boldsymbol{R}^{\mathbf{2}}$} \\
\cline { 4 - 5 } & & & Lower bound & Upper bound & \\
\hline Total & $<0.001^{* *}$ & 3.796 & 3.571 & 4.021 & 0.853 \\
\hline
\end{tabular}

**Significance was set at $\mathrm{p} \leq 0.01$

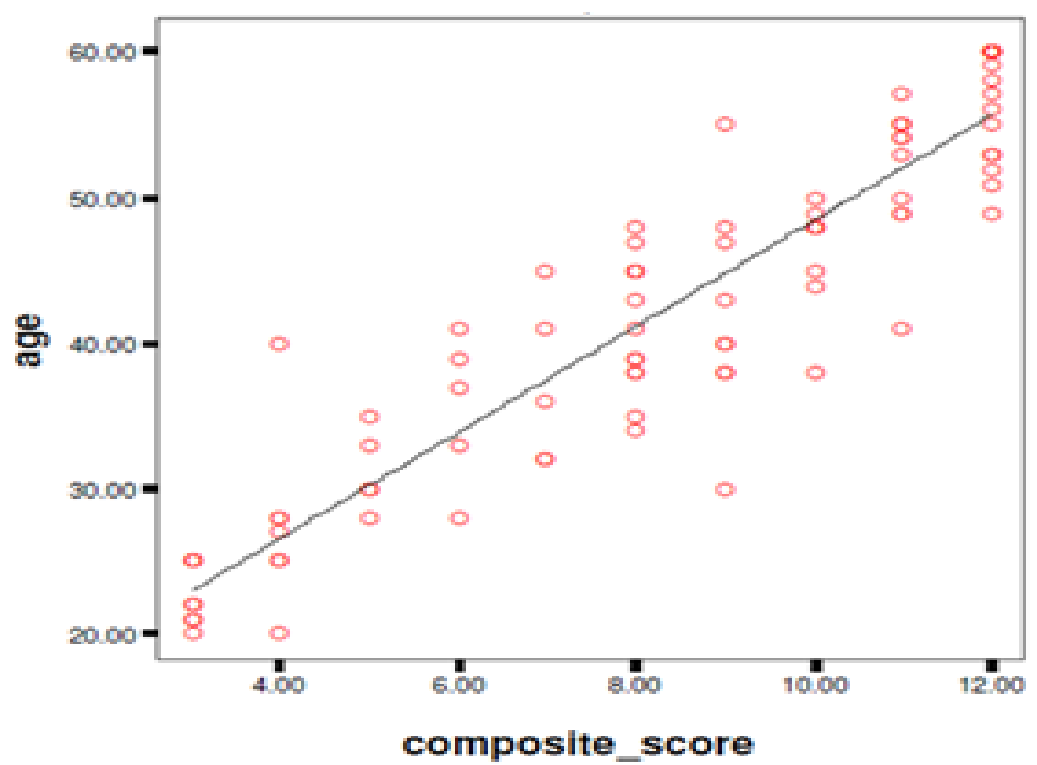

Figure (5): Scatter plot showing the correlation between known age and composite score for the studied group.

\section{Age prediction for the whole studied} subjects:

The actual mean age of the studied subjects was 44.7 years with a minimum of 20 years and a maximum of 60 years. By using the composite score to predict the age of the studied subjects, the predicted mean age had been 44.7 years with a minimum of 23 years and a maximum of 60.9 years respectively (Table 6). Moreover, a significant positive correlation was found between the actual and predicted ages in the studied groups with $\mathrm{R}^{2}$ value $=0.853, \mathrm{p}$ value $<0.001 * *$ (Fig. 6). 
Table (6): Comparison between the mean, minimum and maximum values of actual ages and the predicted ones among the studied group

\begin{tabular}{|c|c|c|c|}
\hline & Mean \pm SD & Minimum & Maximum \\
\hline Known (actual) age & $44.7 \pm 12.2$ & 20 & 60 \\
\hline Predicted age & $44.7 \pm 11.11$ & 23 & 60.8 \\
\hline
\end{tabular}

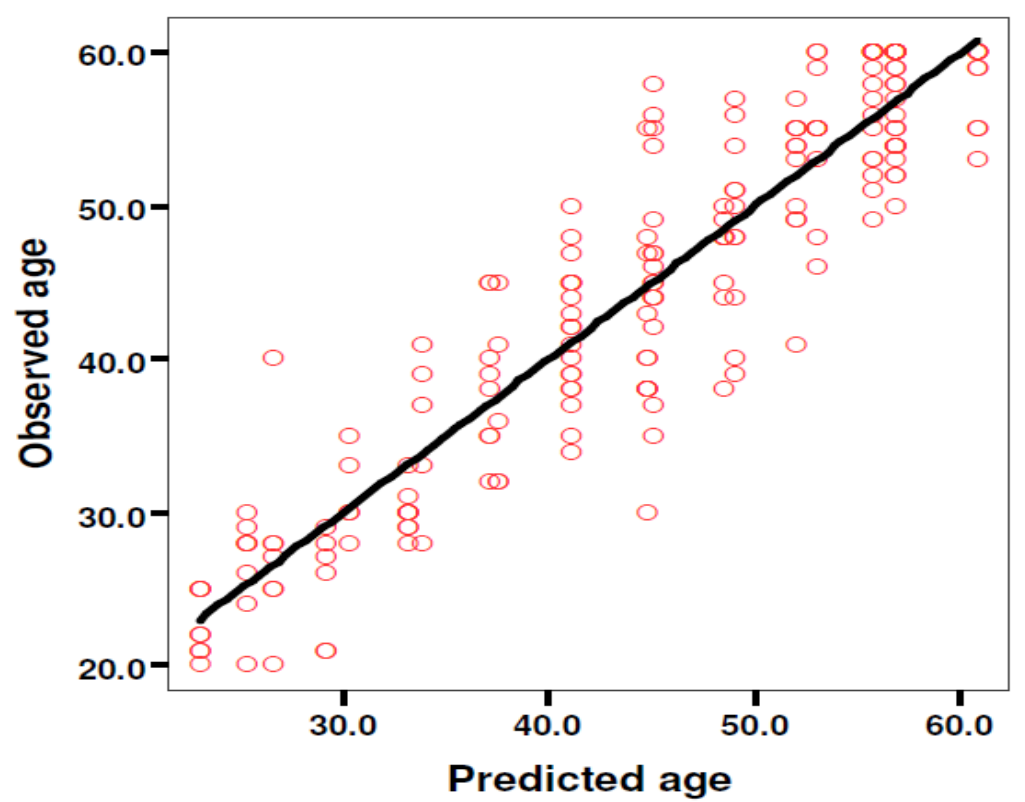

Figure (6): Scatter plot showing correlation between the actual age and the predicted age

\section{DISCUSSION}

Determination of the age from bones is an essential step in forensic identification. Many studies over the past years have been conducted to assess the accuracy of qualitative and quantitative observations to estimate age from bone. As complete dependence on one bone to determine individual's age is not so reliable, it has become necessary to develop new techniques for age estimation from different bones (Bokariya et al.;2011).

Pubic trabeculations was on the same line with Villa et al. (2013) who studied the pubic bone trabecular changes among 319 postmortem CT (recently dead). They detected a significant difference between the pubic trabeculations phases and the different age groups with a higher score in group 4 with the least trabeculations density $(\mathrm{p}<0.001 * *$ for all), similarly they found a positive correlation between age and pubic trabeculations phases.

The current study was also on the same line with Mulhern and Jones (2005), who studied the transverse trabeculations of the pelvic auricular surface of 309 individuals, they scored the transverse trabeculations into 7 phases.

Our current findings concerning the sacral ala trabeculations phases agreed with those of Barrier et al. (2009). They previously studied the trabecular changes in the sacro-pubic bundle of 46 coxal bones by CT 3D reconstruction; they classified the transverse organization of this bundle into 3 scores. They also found a statistical significant difference concerning the 
sacropubic trabeculations score among the different 3 groups $\left(\mathrm{p}<0.001^{* *}\right.$ for all).

Our findings were also on the same base as those of Wade et al. (2011) who examined the correlation between age at death and the changes in the trabecular architecture of the human pubic bone.

Moreover, these results went with those of Thomsen et al. (2013) who studied the trabeculations in the second lumbar vertebra by using micro slice CT with 3D reconstruction and reported that this trabecular bone fraction decreased significantly with age for both women and men.

Furthermore, our findings were on the agreement with Turunen et al. (2013). They studied the trabecular changes in the greater trochanter of femur, femoral neck and the calcaneus bones of 20 male cadavers, In addition, our results went on the same line with Froidmont et al. (2013) who studied the trabecular changes in long bones (femur \& humerus).

Our results didn't match with Ding \& Hivid (2000) who studied the changes in trabecular thickness of human tibial cancellous bone. They took samples from 40 tibias bones (30 males and 10 females) and scanned them with micro CT, They detected that the three-dimensional trabecular thickness was lowest in the old age group $(\mathrm{p}<0.003 * *)$, with no difference between young and middle age groups. The discrepancy between these findings and the results of our study may be due to the anatomically different bony area, the different technique and sample size.

These finding concerning the correlation between the decreases in trabeculations density with increasing age was clarified formerly by Martin (2007), Clarke (2008) and Usha and Nandeesh (2012) as they stated that, bone, is like any other tissue, is not immune to aging which lead to decrease in the bone sensitivity to respond to hormonal and non-hormonal regulator for bone formation and resorption. With a net result of increase in resorption and steady or even decrease (depends on genetic background) in bone formation; that's why bone trabeculations decrease with aging.

By using the composite score to predict the age in the studied subjects, we found a significant positive correlation between the actual and predicted ages in the studied groups with $\mathrm{R} 2$ value $=0.853, \mathrm{p}$ value $<0.001 * *$

\section{CONCLUSION}

For forensic age determination, the CT scan trabeculations of the pubic, sacral body and sacral ala were classified into four phases and the differences between groups were studied. Highly statistically significant differences and correlations were detected between the four groups and the studied bones' trabeculations. More accurate age prediction was detected when the composite score of the three bones was used with $\mathrm{R}^{2}$ value $(0.853)$. The predicted regression equation formula for age based on composite score is presented as: Age $=6.696+$ $3.796 \times$ composite score

\section{RECOMMENDATIONS}

1- Further researches concerning the forensic anthropology should be performed as the mass disasters and military conflicts are increasing all over the world leaving behind numerous 
human skeletons and bones for forensic identifications.

2-More studies are required including larger sample size, with different geographical regions and ethnic origins to fulfill the need of developing new standards for identification of age from pelvic CT.

3- Linear regression is population specific so there is an increasing need for further confirmation about the presence of morphometric differences between the different population groups

\section{REFERENCES}

Barrier, P.; Dedouit, F.; Braga, J. et al. (2009): Age at death estimation using multislice computed tomography reconstructions of the posterior pelvis, J. Forensic Sci.; 54: 773-778.

Bokariya, P., Chowdhary, D. S., Tirpude, B. H.; et al.; (2011): A Review of the Chronology of Epiphyseal Union in the Bones at Knee and Ankle Joint, J Indian Acad. Forensic Med.; 33(3): 258260.

Clarke, B. (2008): Normal bone anatomy and physiology. Clin. J. Am. Soc. Nephrol.; 3: S131-S139.

Dempster, D. (2006): Anatomy and functions of the adult skeleton. In: Primer on the metabolic bone diseases and disorders of the mineral metabolism, Favus, M., (Eds.) $6^{\text {th }}$ ed. Washington, the American Society for Bone and Mineral Research, pp: 9.

Ding, $M$ and Hvid, I. (2000): Quantification of age-related Changes in the structure model type and trabecular thickness of human tibial cancellous bone, Bone; 26(3): 291-295.
Franklin, D. (2010): Forensic age estimation in human skeletal remains: current concepts and future directions. Leg. Med.; 12(1):1-7.

Froidmont, B.; Grabherr, S.; Vaucher, P. et al. (2013): Virtual anthropology: A comparison between the performances of conventional X-ray and MDCT in investigating the trabecular structure of long bones, Forensic Sci. Int.; 225: 53- 59.

Martin, G. (2007): Biology of aging. In: Cecil Medicine. Goldman, L. and Ausiello, D. (Eds.), $23^{\text {rd }}$ edition. Philadelphia, Saunders Elsevier, pp: 276-290.

Mulhern, M. and Jones, E. (2005): Test of revised method of age estimation from the auricular surface of the ilium. Am. J. Phys. Anthropol.; 126:61-65.

Shetty, U. (2009): Macroscopic study of cranial suture closure at autopsy for estimation of age, Anil Aggrawal's Internet J. Forensic Med. and Toxicol.; 10(2).

Thomsen, J.S.; Niklassen, A.S.; Ebbesen, E.N. et al.; (2013): Agerelated changes of vertical and horizontal lumbar vertebral trabecular 3D bone microstructure is different in women and men, Bone; 57: 47-55.

Turunen J.M.; Prantner, V.; Jurvelin, J. et al. (2013): Composition and microarchitecture of human trabecular bone change with age and differ between anatomical locations, Bone; 54: 118-125.

Usha, K. and Nandeesh, B.N. (2012): Radionuclide and Hybrid Bone Imaging. In Physiology of Bone Formation, Remodeling and 
Metabolism. Fogelman, I. (Eds.), $2^{\text {nd }}$ edition. Berlin, SpringerVerlag, pp: 29-55.

Villa, C.; Normand, M. H.; Buckberry, J. et al. (2013): Forensic age estimation based on the trabecular bone changes of the pelvic bone using post-mortem CT. Forensic Sci. Int.; 233: 393-402.

Wade, M.A.; Nelson, A.; Garvin, G. et al. (2011): Preliminary Radiological Assessment of Age Related Change in the Trabecular Structure of the Human Os Pubis, J. Forensic Sci.; 56: 312-319. 


\section{الملخص العربي}

تقدير العمر عن طريق تقييم تربك عظام الحوض باستخدام الاثعة المقطعية

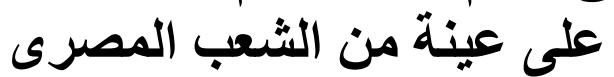

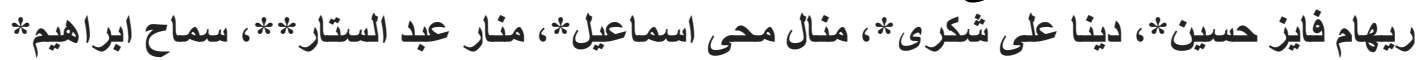

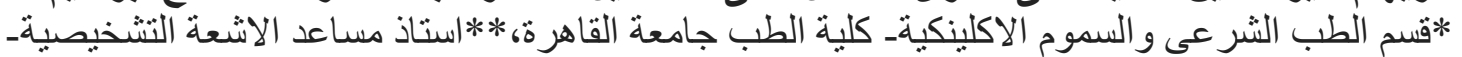

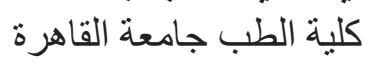

نظر ال اهميته الكبيره من الناحيه البحثيه و ايضا الناحيه القانونيه فان الانثروبولجيا الثر عيه في

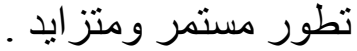
اجريت هذه الدر اسة في قسم الأشعة - بمستشفي قصر العيني وذللك باجر اء اشععه مقطعيه لمنطقه الحوض و البطن ل 200 شخص تتر اوح حأعمار هم من 20 إلى 60 عام في خلال الفتره من اكتوبر 2015

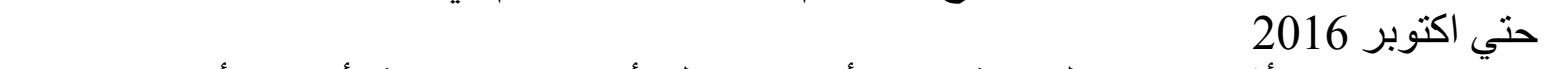
تم تصنيف الأشخاص قيد الدراسة، وفقا لأعمار هم، إلى أربع فئات عمرية بأخذ 10 أعو ام فرق بين

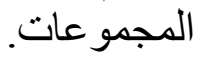
ولتحديد العمر ، أستخدمت الأشعة المقطعية لعظام العانة و العجزية والآلا العجزية و قمنا بتقبيميم

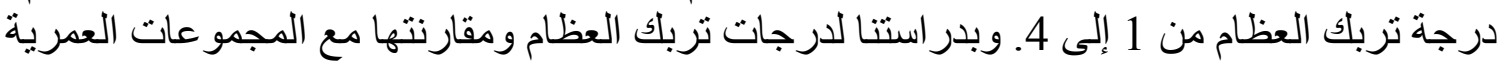

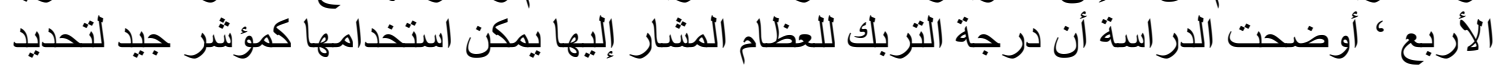

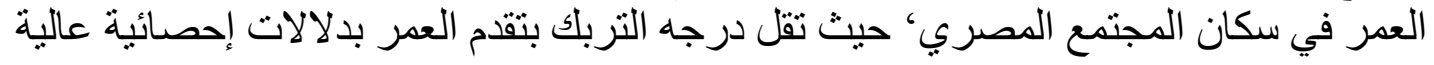

